\title{
Mortality among "never smokers" living with smokers: two cohort studies, 1981-4 and 1996-9
}

\author{
Sarah E Hill, Tony A Blakely, Ichiro Kawachi, Alistair Woodward
}

Papers pp 977, 989

Department of Public Health, Wellington School of Medicine and Health Sciences,

PO Box 7343,

Wellington South,

New Zealand

Sarah Hill

public health medicine

registrar

Tony Blakely

senior research fellow

Alistair Woodward

professor of public

health

Department of

Health and Social

Behavior, Harvard

School of

Public Health,

677 Huntington

Avenue, Boston,

MA 02115, USA

Ichiro Kawachi

professor of social

epidemiology

Correspondence to:

T A Blakely

tblakely@

wnmeds.ac.nz

BMJ 2004;328:988-9
Few studies have examined the association between passive smoking and all cause mortality; most of these have had limited study power. ${ }^{1-4}$ We present results from two population cohorts of adults who had never smoked ("never smokers"), followed for three year mortality according to household exposure to secondhand smoke.

\section{Participants, methods, and results}

The two cohorts comprised all New Zealand adults aged 45-74 years who responded to the 1981 and 1996 censuses and who identified themselves as never smokers, lived in a private dwelling (that is, not a prison, hospital, or other institution), and had provided data on smoking status for all household members aged 15 and over ( $87.0 \%$ of never smokers in 1981 and $85.3 \%$ in 1996).

Never smokers living in households with one or more current smokers were regarded as being exposed to secondhand smoke in the home; those living in households with no current smokers were regarded as not exposed. Cohort members were followed for mortality in the three years after the census by means of anonymous probabilistic linkage with a national register of mortality records. ${ }^{5}$ Record linkage was complete for $71.0 \%$ of eligible mortality records during 1981-4 and for $78.2 \%$ during 1996-9. Data were weighted to adjust for potential linkage bias. ${ }^{5}$

We calculated mortality and standardised for age and ethnicity using the 1996 census population as the standard. We used Poisson regression to adjust for age, ethnicity, marital status, and socioeconomic position, using a more restricted cohort with full demographic data $(82.3 \%$ of the 1981 cohort and $89.9 \%$ of the 1996 cohort).
In both cohorts and sexes, mortality among never smokers was greater in those living in households with a current smoker (table).

\section{Comment}

Among adults who had never smoked we found a modest but consistent association between exposure to secondhand smoke in the home and mortality. This association persisted after adjustment for age, ethnicity, marital status, and socioeconomic position. The finding of about $15 \%$ excess mortality in never smokers exposed to secondhand smoke at home is consistent with the previous largest study in this area. ${ }^{1}$

Mortality and mortality rate ratios were standardised by age and ethnicity, and further adjustment for marital status and socioeconomic position altered the results only slightly. This suggests that these factors were not important confounders (independent of age and ethnicity). We could not adjust directly for lifestyle characteristics as these data are not included in the census. However, lifestyle factors are unlikely to act as important confounders when there is no confounding by socioeconomic position.

We considered exposure to secondhand smoke in the home only. Our inability to measure exposure in other settings introduces a degree of exposure misclassification; mortality rate ratios will probably be underestimated as a consequence. We suspect that this misclassification will be greater for the 1981-4 cohort,

A security statement about the New Zealand census-mortality + study (NZCMS) is on bmj.com

This article was posted on bmj.com on 5 April 2004: http://bmj.com/cgi doi/10.1136/bmj.38070.503009.EE

All cause mortality among adults who have never smoked, by household exposure to secondhand smoke, 1981-4 and 1996-9

\begin{tabular}{|c|c|c|c|c|c|}
\hline \multirow[b]{2}{*}{ Cohort } & \multirow[b]{2}{*}{ No of deaths } & \multirow[b]{2}{*}{ Person years } & \multirow{2}{*}{$\begin{array}{l}\text { Standardised mortality (per } \\
100000 \text { a year) }\end{array}$} & \multicolumn{2}{|c|}{ Rate ratio ( $95 \%$ confidence interval) } \\
\hline & & & & Standardised ${ }^{*}$ & Adjusted† \\
\hline \multicolumn{6}{|l|}{$1981-4$} \\
\hline \multicolumn{6}{|l|}{ Men: } \\
\hline No exposure & 3240 & 211852 & 1530.4 & & \\
\hline Exposure & 846 & 57344 & 1683.6 & 1.10 (0.99 to 1.22$)$ & $1.17(1.05$ to 1.30$)$ \\
\hline \multicolumn{6}{|l|}{ Women: } \\
\hline No exposure & 4902 & 435423 & 1009.8 & & \\
\hline Exposure & 1200 & 138675 & 1050.4 & $1.04(0.96$ to 1.13$)$ & 1.06 (0.97 to 1.16$)$ \\
\hline \multicolumn{6}{|l|}{ 1996-9 } \\
\hline \multicolumn{6}{|l|}{ Men: } \\
\hline No exposure & 3684 & 387292 & 1024.6 & & \\
\hline Exposure & 687 & 63244 & 1198.3 & $1.17(1.05$ to 1.31$)$ & 1.16 (1.04 to 1.30$)$ \\
\hline \multicolumn{6}{|l|}{ Women: } \\
\hline No exposure & 4026 & 578216 & 671.6 & & \\
\hline Exposure & 756 & 100507 & 854.8 & $1.27(1.15$ to 1.41$)$ & 1.28 (1.16 to 1.42$)$ \\
\hline
\end{tabular}

Raw numbers are randomly rounded to a near multiple of three, as per Statistics New Zealand's protocol. (Mortality and regression analyses are calculated using exact counts.)

${ }^{*}$ Standardised by age (five year age bands) and ethnicity (Maori, Pacific, and neither Maori nor Pacific).

†Adjusted for age, ethnicity, marital status, and socioeconomic position (that is, education, labour force status, household equivalised income, household car access, housing tenure, and small area deprivation index). 


\section{What is already known on this topic}

Few studies have examined the link between exposure to secondhand smoke and mortality

\section{What this study adds}

Adults who had never smoked and who lived with smokers had about $15 \%$ higher mortality than never smokers living in a smoke-free household

This study strengthens the case for a causal association between secondhand smoke and mortality

as smoking and exposure to secondhand smoke outside the home were more prevalent in New Zealand in the early 1980s. This may explain the apparently stronger association between household exposure and mortality in the 1996-9 cohort compared with the 1981-4 cohort.

The results from this study add to the weight of evidence of harm caused by passive smoking and support steps to reduce exposure to other people's smoke-in the home and in other settings.
We thank Jackie Fawcett and June Atkinson for technical help with data extraction and analysis.

Contributors: SEH conceived the study, analysed the data, and drafted the manuscript. TAB conceived and led the New Zealand census-mortality study (NZCMS) from which data for this study were drawn; advised on study design, data analysis, and interpretation; and contributed to the manuscript. AW and IK advised on the design, analysis, and interpretation of the study and contributed to the manuscript. SEH and TAB will act as joint guarantors for this paper.

Funding: The NZCMS is primarily funded by the Health Research Council of New Zealand, with further funding from the Ministry of Health. Funding for SEH's salary came from the New Zealand Population Health Charitable Trust.

Competing interests: None declared.

Ethical approval: Not needed-see security statement on bmj.com

1 Sandler D, Comstock G, Helsing K, Shore D. Deaths from all causes in non-smokers who lived with smokers. Am J Public Health 1989;79:163-7.

2 Svendsen K, Kuller L, Martin M, Ockene J. Effects of passive smoking in the multiple risk factor intervention trial. Am J Epidemiol 1987;126: 783-95.

3 Humble C, Croft J, Gerber A, Casper M, Hames CG, Tyroler HA. Passive smoking and 20-year cardiovascular disease mortality among nonsmoking wives, Evans County, Georgia. Am J Public Health 1990;80:599-601.

4 Hole D, Gillis C, Chopra C, Hawthorne V. Passive smoking and cardioresHole D, Gillis C, Chopra C, Hawthorne V.Passive smoking and cardiores-
piratory health in a general population in the west of Scotland. BMJ 1989;299:423-7.

5 Blakely T, Salmond C, Woodward A. Anonymous linkage of New Zealand mortality and census data. Aust N ZJ Pub Health 2000;24:92-5. (Accepted 5 March 2004)

doi 10.1136/bmj.38070.503009.EE

\section{Effectiveness of nicotine patches in relation to genotype in women versus men: randomised controlled trial}

Patricia Yudkin, Marcus Munafo, Kate Hey, Sarah Roberts, Sarah Welch, Elaine Johnstone, Michael Murphy, Siân Griffiths, Robert Walton

The overall effectiveness of nicotine replacement therapy could be greater if the therapy were targeted at those most likely to respond. Variants of the dopamine D2 receptor (DRD2 $32806 \mathrm{C} / \mathrm{T})$ have been implicated in the initiation and maintenance of smoking, ${ }^{12}$ and these variants may also be related to response to nicotine replacement therapy. ${ }^{3}$ Additionally, mechanisms of nicotine addiction may differ in men and women. ${ }^{4}$ With this evidence in mind, we examined whether the response to nicotine replacement therapy is modified by sex and genotype.

\section{Participants, methods, and results}

A randomised controlled trial of nicotine patches in 1991-2 recruited 1686 heavy smokers ( $\geq 15$ cigarettes a day). ${ }^{5}$ The participants wore patches for 12 weeks. Abstinence from smoking was confirmed at one week by expired carbon monoxide concentration $\leq 10 \mathrm{ppm}$, and at 12, 24, and 52 weeks by salivary cotinine concentration $\leq 20 \mathrm{ng} / \mathrm{ml}$ ( $89 \%$ of cases) or by expired carbon monoxide concentration $\leq 10 \mathrm{ppm}$.

In 1999-2000, we contacted 1532 of the 1625 participants still alive; the mean time from trial to follow up was 8.3 years. In all, 752/1532 (49\%) gave a blood sample from which DRD2 32806 was successfully typed. Reported abstinence at follow up was confirmed by plasma cotinine concentration $\leq 20 \mathrm{ng} / \mathrm{ml}$. Throughout, non-respondents were assumed to be smoking.

Participants were older than non-participants (mean age at entry to trial, 43.0 years $v 41.5$ years; $\mathrm{P}=0.002)$, more likely to be female $(59 \%(445 / 752) v$ $53 \%(410 / 780) ; \mathrm{P}=0.01)$, and more likely to have quit for a year in the trial $(11 \%(82)$ v $4 \%(33), \mathrm{P}<0.0001)$; $744(99 \%)$ reported their racial background as white.

The variant $\mathrm{T}$ allele of the dopamine $\mathrm{D} 2$ receptor DRD2 32806 (CT or TT genotype) was found in $41 \%$ $(183 / 445)$ of women and $41 \%$ of men (127/307). Within each sex, there was no difference between the genotype groups in age, number of cigarettes a day, or dependency score.

We measured effectiveness of the patches by the relative odds of abstinence for active and placebo patches over five cumulative time periods: one week, 12 weeks, 24 weeks, 52 weeks, and to follow up. Treatment by genotype and sex, and their interaction, was examined in a full logistic regression model. The three way interaction by genotype by sex was significant for all time periods $(\mathrm{P}=0.009, \quad \mathrm{P}=0.03, \mathrm{P}=0.006$, $\mathrm{P}=0.006, \mathrm{P}=0.004$ respectively), and we therefore analysed the data for men and women separately.

This article was posted on bmj.com on 19 March 2004: http://bmj.com/ cgi/doi/10.1136/bmj.38050.674826.AE

\section{Papers pp 977,988}

Department of Primary Health Care, University of Oxford, Oxford OX3 7LF Patricia Yudkin reader

continued over

BMJ 2004;328:989-90 